
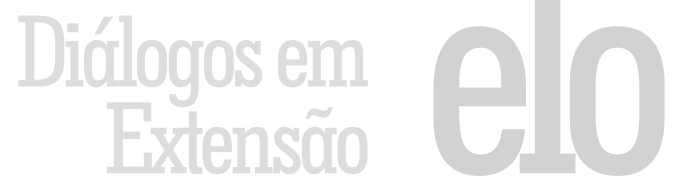

\title{
Oficina de plantas medicinais para vendedores informais das feiras livres de Caetité, Bahia, Brasil
}

Joyce Silva Oliveira ${ }^{1}$ : Lílian Tibo de Souza Pimentel²; Cátia Ionara Santos Lucas ${ }^{3}$; Maria Elizangela Ramos Junqueira ${ }^{4}$; Marileide Dias Saba ${ }^{5}$, Robson de Cássio Santos Dourado ${ }^{6}$

Resumo: O presente trabalho teve como objetivo orientar os vendedores informais e a população sobre o uso racional e seguro das espécies vegetais utilizadas tradicionalmente pelas comunidades locais. A apresentação de palestra, atividades práticas no herbário como confecção de exsicatas, e entrega de cartilha sobre as principais plantas comercializadas no local foram desenvolvidas no Campus VI, UNEB. Destacou-se a urgência em relação às precauções no uso das plantas medicinais, já que imprecisões na sua utilização podem causar sérios problemas à saúde dos usuários.

Palavras chave: Conhecimento popular, etnomedicina, medicina alternativa, vendedores informais.

Áreas temáticas: Cultura, educação e meio ambiente

\section{Workshop onmedicinal plantsforinformal vendorsoffairs at Caetité city, Bahia state, Brazil}

Abstract: The present study aimed to guide thein formal vendorsand people on the rational and secure use of plant species traditionally used by local communities. The presentation conference, hands-on activities such as making the exsiccatae in herbariu mand delivery of primer on the major local traded plants were developed in the Campus VI, UNEB. It showed urgency in precaution sin the use of medicinal plants, as in accuracies in the use can cause serious health problems for users.

Keywords: Alternative medicine, folkknowledge, plants, Ethnomedicine, informal workers.

\section{Taller de plantas medicinales para los vendedores informales de ferias en Caetité, Bahía, Brasil}

Resumen: Esta investigación tuve como objetivo orientar a los vendedores informales y al público sobre el uso legítimo y seguro de las hierbas medicinales. Se produjeron prospectos preparados con la presentación de conferencias

\footnotetext{
${ }^{1}$ Universidade Estadual da Bahia

2 Universidade Estadual da Bahia

3 Universidade Estadual da Bahia

${ }^{4}$ Universidade Estadual da Bahia

5 Universidade Estadual da Bahia

${ }^{6}$ Universidade Estadual da Bahia
} 
$y$ diversas atividades en Campus VI, UNEB. Los resultados señalaran la necesidad de adoptar medidas de precauciones en el uso de las hierbas medicinales, ya que la imprecisión de las cantidades puede producir daños a la salud.

Palabras claves: El conocimiento popular, etnomedicina, la medicina alternativa, vendedores informales.

\section{Introdução}

O município de Caetité, localizado no Sudoeste da Bahia, abrange áreas de Caatinga e Cerrado que, apesar da supressão vegetal resultante das atividades de mineração de muitas empresas que atuam na região, possuem diversas espécies de plantas medicinais utilizadas pela comunidade local e de cidades circunvizinhas.

As plantas medicinais são um recurso acessível, de baixo custo e relativa eficiência principalmente para locais distantes dos grandes centros urbanos e carentes de atendimento médico hospitalar, como o município de Caetité. Contudo, apesar da preferência das comunidades por esse recurso alternativo, o uso indevido ou equivocado pode provocar eventos adversos ou sérios danos que vão desde mal estar, intoxicação, envenenamento, abortos e mortes.

A utilização de plantas medicinais faz parte da cultura da região, sendo transmitida através de relatos orais. Entretanto, nem sempre o uso e manuseio das espécies são realizados de forma correta.

$\mathrm{O}$ projeto de extensão Oficina de Plantas Medicinais, vinculado à Universidade do Estado da Bahia (UNEB), Departamento deCiências Humanas Campus VI, Caetité, visou orientar os vendedores informais que comercializam plantas medicinais na feira livre de Caetité, bem como a população, sobre os critérios científicos para a escolha das amostras, manuseio, uso racional e seguro das espécies vegetais utilizadas tradicionalmente pelas comunidades locais. Aliado à conscientização para a preservação da flora medicinal e da cultura local, o projeto faz resgate e valorização do saber popular, assim como a integração entre academia e sociedade, através da socialização dos saberes popular e científico. Além disso, as oficinas beneficiam a população, uma vez que demonstram alternativas no uso sustentável das plantas, bem como dos produtos comercializados já conhecidos dos moradores desse território, os quais, entretanto, ainda não tinham o aval da ciência.

\section{A história}

O Curso de Ciências Biológicas do Campus VI da UNEB foi implantado em 2006, despertando ainda mais a curiosidade dos jovens da região em relação a diversos assuntos da área, incluindo Botânica. Em 2007, um grupo de graduandos realizou um trabalho com a comunidade local sobre o uso de plantas medicinais e, como já esperado, foi percebida a necessidade de mais estudos.

Assim, em 2008, foi cadastrado o Projeto de Pesquisa "Uso e diversidade de plantas medicinais do município de Caetité, Bahia, Brasil", no Núcleo de Pesquisas e Extensão (NUPE) da UNEB Campus VI, sendo vinculado ao curso de Ciências Biológicas. A equipe do projeto era composta por professores/ pesquisadores, graduandos bolsistas e voluntários, e colaboradores locais. 
Nesse projeto de pesquisa foi realizado o levantamento das espécies utilizadas na feira livre, na comunidade de Santa Luzia e no distrito de Brejinho das Ametistas, todos esses localizados no município de Caetité.

Após o término do estudo proposto, foi preparado o "retorno" da pesquisa para as comunidades, considerando o compromisso ético da etnobotânica conforme Albuquerque, Araújo e Soldati (2008). Dessa forma, a Oficina de Plantas Medicinais foi concebida como atividade extensionista vinculada ao referido projeto de pesquisa "Uso e diversidade de plantas medicinais no município de Caetité, Bahia, Brasil”, estando de acordo com os princípios do Código de Ética da Sociedade Internacional de Etnobiologia (ISE, 2010), que estabelece diretrizes para o trabalho com comunidades tradicionais e locais, como é o caso de Caetité. O referido código determina que pesquisadores devolvam o retorno das informações obtidas com as pesquisas, através da divulgação dos resultados e outras atividades para os colaboradores do trabalho.

Dessa forma, a divulgação do conhecimento sistematizado no projeto de pesquisa, a partir de uma ação de retorno dos pesquisadores para a comunidade do município de Caetité, foi planejada mediante princípios freirianos. Tais princípios se baseiam numa concepção de valorização da cultura, do respeito, do diálogo, da ética e da integração de diferentes saberes (FREIRE, 2004).

\section{Desenvolvimento das atividades}

As atividades da oficina foram realizadas no Departamento de Ciências Humanas, Campus VI da UNEB no município de Caetité, Bahia, situado na região da Serra Geral, distante 757 quilômetros da capital do estado, Salvador, possuindo, em 2007, 46.192 habitantes. Ocupa uma área de 2.306,382 km², possui altitude de 825 metros, clima ameno, apesar de situada no Semiárido, apresenta características de cerrado e caatinga (IBGE, 2007).

O ápice das atividades previstas na Oficina de Plantas Medicinais ocorreu no mês de novembro de 2010, no Campus VI da UNEB, com o suporte do NUPE, e da equipe técnica responsável pelo projeto de pesquisa "Uso e diversidade de plantas medicinais no município de Caetité, Bahia, Brasil", além da concessão de bolsas de extensão pela Pró-Reitoria de Extensão (PROEX) da UNEB.

O público alvo foi predominantemente vendedores informais de plantas medicinais da feira livre de Caetité, porém, alunos de graduação, professores e crianças das comunidades de origem dos colaboradores também participaram da oficina.

Durante os meses anteriores ao evento ocorreu o planejamento e organização dos procedimentos. A divulgação da oficina foi realizada por meio de cartazes, folders, além de convites e camisetas entregues diretamente aos colaboradores. Nesse período, foram elaboradas palestra para apresentação ao público e cartilha de Plantas Medicinais utilizadas nas feiras livres do município, com linguagem clara e acessível ao público alvo. 
$\mathrm{Na}$ cartilha foram sistematizados, além de dados publicados para as espécies medicinais no Brasil, conhecimentos populares disseminados pela população local sobre as plantas.

O conteúdo da cartilha abrangeu as seguintes informações: a) principais plantas citadas pelos colaboradores; b) nome conhecido pela comunidade local; c) nome conhecido pela comunidade científica; d) característica da planta; e) utilização popular; f) utilização certificada pela ciência e g) outras observações. O material incluía ilustrações e linguagem fácil para a compreensão dos colaboradores.

A elaboração de cartilhas corrobora os pressupostos de Albuquerque, Araújo e Soldati (2010), que indicam esse material como um dos instrumentos metodológicos para o "retorno" da pesquisa etnobotânica, ou seja, como contribuição dos pesquisadores às comunidades. Nesse sentido, as cartilhas constituem-se uma estratégia privilegiada, devido ao fato destas poderem ser utilizadas para documentar as espécies de plantas e os seus usos, associando, sobretudo, o conhecimento local ao científico.

Inicialmente foi proferida uma palestra em uma das salas do Campus, apresentando os principais resultados obtidos até aquele momento, os quais incluíam informações teóricas sobre plantas medicinais comercializadas no município, além de imagens das espécies selecionadas, dos locais visitados, dos encontros entre os pesquisadores e vendedores e de cenas do trabalho desenvolvido durante o projeto.

Foi promovido um "chá", utilizando as espécies citadas na pesquisa, para a confraternização dos participantes da oficina. E, posteriormente, a equipe do projeto de extensão conduziu o grupo para uma visita ao Laboratório de Botânica, com a finalidade de explicar o processo de herborização das plantas coletadas (preparo das espécies medicinais para serem armazenadas para estudos), e ao Herbário HUNEB-Coleção Caetité (local destinado para o depósito das espécies vegetais desidratadas). Nesse último espaço, foi apresentada a coleção de plantas medicinais relacionadas ao projeto e foram dadas as instruções para que os mesmos montassem uma exsicata, forma na qual as plantas são preservadas para serem depositadas no herbário.

Ao final das atividades e após as contribuições culturais e científicas do grupo do projeto, foi entregue a cada pessoa inscrita na oficina um kit com uma cartilha informativa, uma camiseta e uma xícara da oficina.

\section{Refletindo sobre os resultados da oficina}

Devido à concretização da divulgação dos resultados do projeto, foi possível confirmar a utilização de 45 espécies medicinais comercializadas nas feiras livres de Caetité (Figura 1), dentre as 60 espécies citadas.

Para Sieber e Albuquerque (2010), os encontros, oficinas e reuniões são as principais táticas participativas realizadas nesse tipo de trabalho, uma vez que os mesmos possibilitam, de forma coletiva, momentos de reflexão e discussão com os participantes sobre a gestão de recursos naturais da comunidade, aliado à motivação para a participação das pessoas em um processo dinâmico. 


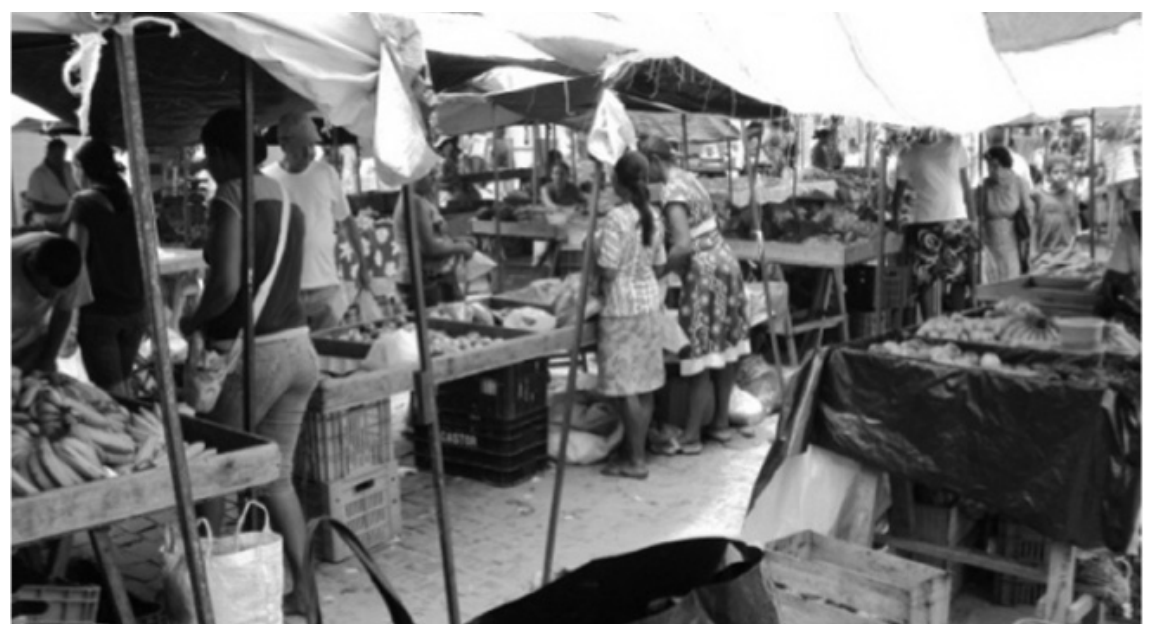

Figura 1 - Imagem da feira livre, município de Caetité - BA.

Os estímulos visuais empregados na apresentação oral do evento possibilitam a integração, o diálogo e trocas, e estão de acordo com orientações de pesquisadores da área de Etnobotânica (SIEBER, ALBUQUERQUE, 2010).

A utilização de recursos como fotografias e banners fez com que os colaboradores se identificassem dentro da pesquisa apontando os locais de coletas, quais plantas eles haviam indicado e ajudado a coletar. Esse foi um momento emocionante e crucial, pois os mesmos conseguiram perceber, de fato, o quanto o seu conhecimento é importante, o que proporcionou uma elevação da sua autoestima, num clima de descontração, reconhecimento e troca de informações.

Durante a oficina houve outros momentos marcantes como um encontro de gerações culturalmente diversas. No espaço encontravam-se, como participantes da oficina, professores universitários, colaboradores que não possuíam escolarização formal, e crianças em fase de escolarização. Essa relação entre idades e culturas distintas deve ser motivada, pois viabiliza o respeito, solidariedade e a aprendizagem através da convivência.

A atividade foi um marco histórico do projeto, já que proporcionou a percepção da importância de valores sociais, repercutindo na integração dos colaboradores. Estes se identificaram como sujeitos do projeto, além de obterem reconhecimento por parte da academia como os principais detentores de saberes para realização do trabalho, evidenciando sua contribuição e a importância de cada um deles para o desenvolvimento da ciência.

\section{Considerações finais}

Apesar da existência de informações similares, tanto nos saberes da ciência como nos saberes da comunidade, são necessários cuidados para o uso e indicação das plantas medicinais. Algumas espécies vegetais possuem contra indicação, ou até mesmo indicação equivocada no senso comum, o que pode causar problemas como um breve mal estar, intoxicação, abortos ou até morte. 
Para a ampliação do trabalho das oficinas, que consiste no esclarecimento quanto ao uso das plantas, além da valorização dos conhecimentos populares, faz-se urgente o incentivo de novas pesquisas que possam testar a ação e eficácia das substâncias presentes nas espécies utilizadas pelas comunidades. Além disso, também é urgente propor estratégias de preservação das plantas que sofrem maior pressão de extermínio na natureza.

Foram notórios os benefícios do projeto de pesquisa e desse programa extensionista de oficina de plantas medicinais, integrando a comunidade com a academia, apresentando-se como uma oportunidade para futuras ações e pesquisas. Entretanto, não foi possível ainda viabilizar melhores condições de trabalho para os feirantes, como melhoria da infraestrutura de suas barracas de vendas, elaboração de cursos sobre o manuseio e a forma de armazenamento dos vegetais medicinais.

A população de Caetité ainda utiliza os saberes tradicionais, transmitidos através da oralidade. Com o projeto de extensão "Oficina de plantas medicinais" foi concretizada a disseminação dos conhecimentos sistematizados, resultando assim em uma tática bem sucedida, já que poderiam perder-se facilmente por ser de tradição oral, sem registros escritos.

\section{Agradecimentos}

À Pró-Reitoria de Extensão pelas bolsas concedidas aos estudantes; ao Núcleo de Pesquisa, extensão (NUPE); ao Departamento de Ciências Humanas, Campus VI, UNEB pelo apoio financeiro e logístico; aos vendedores informais e comunidade de Caetité pela parceria.

\section{Referências Bibliográficas}

ALBUQUERQUE, U.P.; ARAÚJO, T.A.S.; SOLDATI, G.T. O "retorno" das pesquisas etnobiológicas para as comunidades. In: ALBUQUERQUE, U.P.; LUCENA, R.F.P.; CUNHA, L.V.F.C. Métodos e Técnicas na Pesquisa Etnobiológica e Etnoecológica. NUPPEA, Recife, 2010. 560p.

FREIRE, P. Pedagogia da Autonomia: saberes necessários à prática educativa. São Paulo, Paz e Terra, 2004. 146p.

IBGE. Instituto Brasileiro de Geografia e Estatística. Números de Habitantes e área territorial. Disponível em: <http://www.ibge.gov.br/ home>. Acesso em: 13 de nov. 2010.

ISE. International Society of Ethnobiology. Código de Ética. Disponível em: 〈http://www.globaldiversityfund.net/node/503>. Acesso em: 13 nov. 2010.

SIEBER, S.S.; ALBUQUERQUE, U.P. Métodos Participativos na Pesquisa Etnobiológica. In. ALBUQUERQUE, U.P.; LUCENA, R.F.P.; CUNHA, L.V.F.C. Métodos e Técnicas na Pesquisa Etnobiológica e Etnoecológica. NUPPEA, Recife, 2010. 560p. 